\title{
AN OVERVIEW OF THE ECO-FRIENDLY LYOCELL FIBRE
}

\section{ANITHA B \& PRIYANKA R}

Lecturer/Garment Technology, V.S.V.N.Polytechnic College, (Autonomous), Virudhunagar, Tamil Nadu, India

KEYWORDS: NMMO, Cellulose, Dope, Dissolution, Crystallinity, Orientation, Amorphous, Skin contact comfort \& Fibrillation
\end{abstract}

Received: Jul 07, 2021; Accepted: Jul 27, 2021; Published: Aug 03, 2021; Paper Id: IJTFTDEC20212

\section{INTRODUCTION}

Lyocell fibers were first manufactured as Tencel ${ }^{\mathrm{TM}}$ fiber by Courtaulds Fibers, UK, in the 1980s. Lenzing AG, Austria produced lyocell in the brand name of 'Lyocell by Lenzing.' The generic name is 'lyocell,' which is produced in the brand name Lenzing Lyocell (Lenzing), Tencel (Acordis, previously Courtaulds), Newcell (Akzo Nobel), and special brands including Seacell (Zimmer AG). The introduction of lyocell fibre by Courtaulds in 1995 has been one of the most important developments in the area of man-made cellulosic fibres.

Apart from the environmental eminence, the Lyocell fibres possess high quality. In the wet state, they are proclaimed to have high strength and exceptional tenacity compared to dry state. It furnishes good blendability with other fibres and incomparable draping characteristics.

\section{MANUFACTURE OF LYOCELL FIBRES}

Lyocell fibre incorporate cellulose as predominant chemical compound, a linear chain polymer present in the cells of every plant. For Lyocell manufacture, the cellulose is acquired from the wood pulp of hard bark of trees. Some prevalent tree species used include Oak and Birch. The tresses are grown on managed tree farms, generally on land that is not suitable for other agriculture. The key steps for Lyocell fibre manufacture are shown in figure: 1 


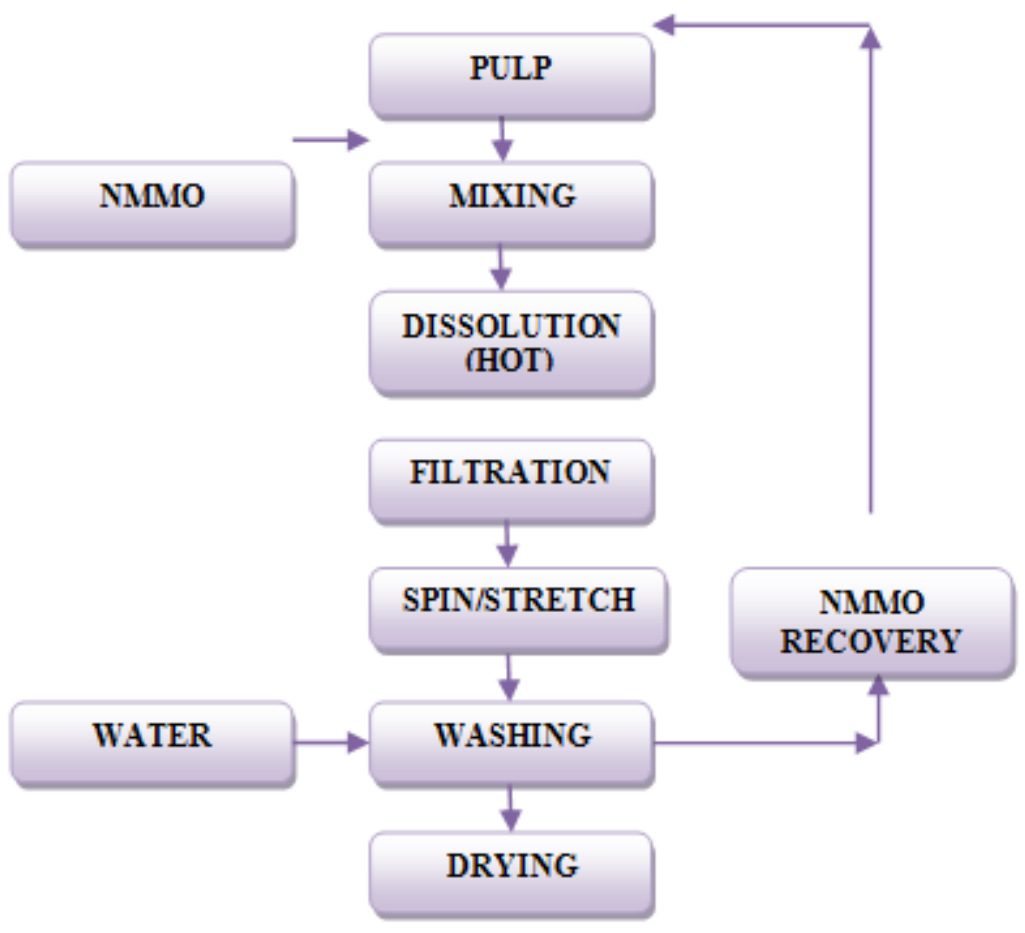

Figure 1: Flow Chart Showing Key Steps for Lyocell Fiber Manufacture.

The Manufacturing process of Lyocell fibre involves

- Dope formation of the starting cellulose in NMMO- water mixture.

- At elevated temperature, dislodgement of the highly viscous dope through an air gap into a precipitation bath (Dry-Jet Wet Spinning).

- The Coagulation of cellulose fibre which takes place in the precipitation bath.

- Post treatment of the Cellulosic fibre followed by Washing and Drying.

- Rehabilitation of the NMMO from the precipitation and washing baths.

The differences between the Lyocell process and the Viscose process with respect to process parameters are listed in Table: 1

Table 1: The Differences between the Lyocell Process and the Viscose Process with Respect to Process Parameters

\begin{tabular}{|c|c|c|}
\hline Process & Lyocell Process/Fibres & Viscose Process/Fibres \\
\hline Dissolution & $\begin{array}{l}\text { - } \\
\text { - WMMO Direct Dissolution } \\
\text { carried out }\end{array}$ & $\begin{array}{ll}\text { - } & \text { Steeping, shredding, Ageing } \\
\text { - } & \text { Mercerization/Xanthation } \\
\text { - } & \text { Dissolution, Ripening }\end{array}$ \\
\hline Spinning & $\begin{array}{l}\text { - Dry Jet Wet Spinning } \\
\text { - The polymer is dissolved in relevant solvent to } \\
\text { make the polymer solution, which is then extruded } \\
\text { under heat and pressure into the air gap before it } \\
\text { enters a coagulation bath } \\
\text { - In this process, spinneret is kept just outside the } \\
\text { surface of coagulation bath }\end{array}$ & $\begin{array}{l}\text { - Wet Spinning } \\
\text { - Dopes with relatively low } \\
\text { viscosity. } \\
\text { - Fibres are formed using } \\
\text { Spinneret immersed on } \\
\text { aqueous bath containing } \\
\text { sulphuric acid and additives }\end{array}$ \\
\hline
\end{tabular}




\begin{tabular}{|c|c|c|}
\hline Environment & $\begin{array}{ll}- & \text { Environmental Friendly } \\
\text { - } & >99 \% \text { of the solvent recovered } \\
\text { - } & \text { Non toxic by-products formed } \\
\text { - } & \text { Tremendous energy demand for } \\
\text { - } & \text { Recycling of solvent }\end{array}$ & $\begin{array}{l}\text { - Heavy Environmental loads } \\
\text { - } \text { CS2 (about 25-30\%) not } \\
\text { recovered. } \\
\text { - } \text { High demand for water }\end{array}$ \\
\hline
\end{tabular}

\section{Dope Preparation}

A $50 \%$ to $60 \%$ of aqueous NMMO is used for making pulp in the preparation of spinning dope. In this process, slurry of aqueous solution of NMMO and cellulose pulp is produced. To prevent the degradation of cellulose, desirable additives are supplemented. The composition and the Desirable additives used in Dope preparation is given in Table: 2

Table 2: The Composition and the Desirable Additives used in Dope Preparation

\begin{tabular}{|c|l|c|}
\hline \multicolumn{2}{|c|}{ Composition } \\
\hline S. No & \multicolumn{1}{|c|}{ Ingredients } & Percentage \\
\hline 1 & NMMO & $50 \%$ to $60 \%$ \\
\hline 2 & Water & $20 \%$ to $30 \%$ \\
\hline 3 & Pulp Desirable Additives \\
\hline \multicolumn{2}{|c|}{$10 \%$ to $15 \%$} \\
\hline 4 & $\begin{array}{l}\text { Anti Oxidant } \\
\text { (N Propyl Gallate - PG) }\end{array}$ & $0.01 \%$ to $0.10 \%$ \\
\hline
\end{tabular}

The surplus amount of water present is dislodged by the evaporation process under controlled pressure. The temperature is maintained below $150^{\circ} \mathrm{C}$; until the cellulose is diffused and homogenous solution is obtained.

The N-O group is formulated by the covalent bond. The oxygen atom possesses the highest electron density. The polarity of the N-O bond is found to be tremendous. Because of this property in the structure of bond, NMMO has a very dreadful dissolving capacity in water and noticeable tendency to contour the hydrogen bonds with cellulose. The NMMO can disrupt the hydrogen bond network of cellulose, when the temperature attains a certain degree and form solvent complexes by establishing new hydrogen bonds between the cellulose and NMMO. The bond is formed in Crystalline as well as in amorphous forms. Decisively, a new and restructural hydrogen bond network is entrenched, which ends in cellulose dissolution. The exertion of dissolving cellulose in NMMO is presented in figure 2.

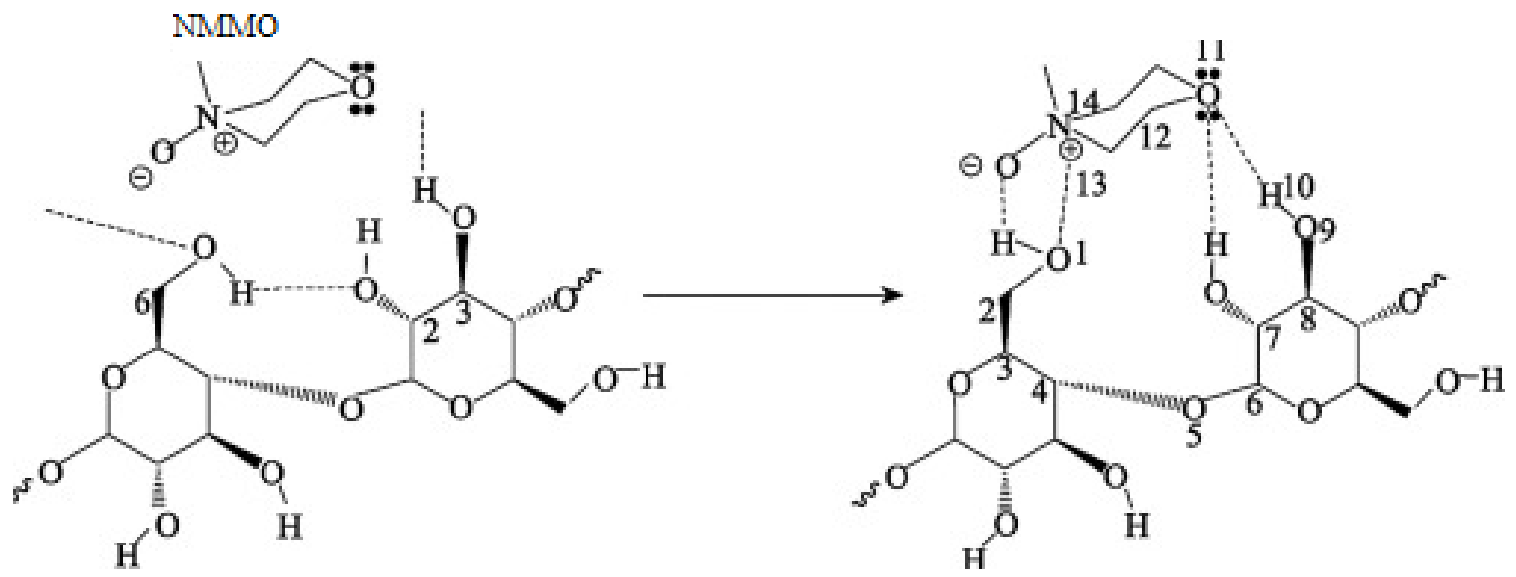

Figure 2: The Exertion of Dissolving Cellulose in NMMO. 


\section{Spinning Process of Lyocell Fibre}

Lyocell fibre spinning is carried out at inflated temperatures ranging from $90^{\circ} \mathrm{C}$ to $120^{\circ} \mathrm{C}$. The fibres are exerted by Dry-Jet Wet Spinning process in NMMO-Water solution. Air gaps ranges from $20 \mathrm{~mm}$ to $250 \mathrm{~mm}$. The spinning Dope is squeezed out from a block Spinneret. The pore diameter of spinneret is categorized from $4 \mathrm{~mm}$ to $100 \mathrm{~mm}$ and the range of capillary tube is from $200 \mathrm{~mm}$ to $800 \mathrm{~mm}$ long. It was fabricated for high concentrations and viscosity of the spinning dope which characterize the strength properties of Lyocell and the endurance of spinning process. The squeezed out filaments from spinneret through air gap and then trailed into the spinning.

The parameters determining spinning process include air gap length, coagulation temperature, spinning speed and draw ratio. The spinning speed and draw ratio will impinge the crystallinity, birefringence and Orientation of the fibre. Parameters in spinning are given below in Table: 3 .

Table 3: Parameters in Spinning

\begin{tabular}{|c|l|l|}
\hline \multicolumn{3}{|c|}{ Parameters in Spinning } \\
\hline S. No & \multicolumn{1}{|c|}{ Parameter } & \multicolumn{1}{c|}{ Details } \\
\hline 1 & Spinning Speed & $20 \mathrm{~m} / \mathrm{min}$ to $40 \mathrm{~m} / \mathrm{min}$ \\
\hline 2 & Air gap Length & $10 \mathrm{~mm}$ to $50 \mathrm{~mm}$ \\
\hline 3 & Coagulation Temperature & $15^{\circ} \mathrm{C}$ to $25^{\circ} \mathrm{C}$ \\
\hline 4 & Coagulation concentration & $10 \%$ to $25 \%$ \\
\hline 5 & Draw Ratio & $2-6$ times \\
\hline
\end{tabular}

\section{Structural Properties of Lyocell Fibre}

The individual characteristics of the textile micro structure influences skin contact comfort. Lyocell fibre structure has some variations compared to viscose fibre. Lyocell fibre has skin-core structure. The outer portion of the Lyocell fibre is very thin with reduced degree of crystallinity. The interior portion of the fibre is composed of numerous fibrils, has an increased degree of orientation and the cellulose crystals are extraordinarily parallel in longitudinal direction of fibre. In contrast, viscose fibres have lower crystallinity and lower orientation. Table: 4 shows the structural parameters of Lyocell and Viscose fibre.

Table 4: Structural Parameters of Lyocell and Viscose

\begin{tabular}{|c|l|c|c|}
\hline \multicolumn{4}{|c|}{ Structural Parameters of Lyocell and Viscose } \\
\hline S. No & \multicolumn{1}{|c|}{ Parameter } & Lyocell & Viscose \\
\hline 1 & Degree of Polymerisation & $550-650$ & $290-320$ \\
\hline 2 & Crystallinity \% & 62 & 39 \\
\hline
\end{tabular}

From table: 4, it is clear that Lyocell fiber is high crystalline than Viscose fiber. Property Comparison among the cellulosic fibres is given in table: 5

Table 5: Property Comparison among the Cellulosic Fibres

\begin{tabular}{|c|l|c|c|c|}
\hline \multicolumn{5}{|c|}{ Property Comparison among the Cellulosic Fibres } \\
\hline S. No & \multicolumn{1}{|c|}{ Property } & Lyocell & Viscose & Cotton \\
\hline 1 & $\begin{array}{l}\text { Elongation at } \\
65 \% \mathrm{RH} \text { and } 20^{\circ} \mathrm{C}\end{array}$ & 14 & 20 & $7-9$ \\
\hline 2 & Moisture uptake \% & 11.5 & 13 & 8 \\
\hline 3 & Water Retention capacity\% & $60-70$ & $90-100$ & $45-55$ \\
\hline
\end{tabular}




\begin{tabular}{|c|c|c|c|c|}
\hline 4 & $\begin{array}{l}\text { Tenacity }(\mathrm{CN} / \text { tex }) \\
\text { Dry } \\
\text { Wet }\end{array}$ & $\begin{array}{l}36 \\
29\end{array}$ & $\begin{array}{l}25 \\
13\end{array}$ & $\begin{array}{l}20-24 \\
26-28\end{array}$ \\
\hline 5 & Initial Wet Modulus 5\% & $250-270$ & $40-60$ & $100-200$ \\
\hline 6 & Loop Strength(CN/tex) & 19 & 6 & $20-26$ \\
\hline
\end{tabular}

The mechanical property of Lyocell fibres is extremely greater than viscose and cotton. This is due to

- No disintegration of cellulose in spinning as the cellulose chain is lengthy and the intermolecular hydrogen bonds are tenacious.

- Higher Crystallinity

- High orientations in crystalline and amorphous structure of Lyocell

Thermal properties of Lyocell fibre is little bit higher than viscose fibre. Viscose fibre loses its strength above $150^{\circ} \mathrm{C}$. But Lyocell fibre loses its strength above $170^{\circ} \mathrm{C}$. Viscose fibre begins to decompose at $300^{\circ} \mathrm{C}$ while Lyocell fibre decomposes at $400^{\circ} \mathrm{C}$

Fibrillation is one of the prominent properties of Lyocell fibre. It is defined as a longitudinal splitting of a wet fibre into microfiber due to the action of swelling, mechanics and friction. It normally takes place under stress along fibre axis in wet condition and the exhausted intermolecular binding force caused by swelling.

Also, the huge level of amorphous orientation helps to prevent an appreciable lateral cohesion and thus resulting in the formation of fibrillation effect. It is applied in the manufacture of non woven technical products and composites. Although it is undesirable for some applications, the projected fibres create magnificent touch that result in peach skin. Some special treatments are incorporated to improve fibrillation that includes enzyme easy care resins and cross linking chemical treatments.

Besides, the Lyocell fibre offers softness, absorbency, breathability, shape stability, dyeability and luxurious handle of Lyocell fibres are better than viscose fibre.

\section{Practical Applications of Lyocell Fibre}

In contrast to other cellulosic fibres, Lyocell fibre has exemplary inherent properties. It is extensively applied in manufacture of textiles, consumer and Industrial products. Lyocell's tactility resembles silk and drapes sumptuously. Lyocell fibres act as a superior raw material for home textiles products that include Mattresses, Mattress pads, Bed covers and Linens. Lyocell fibre has fewer wrinkles than viscose rayon and cotton. It is exquisite for both Men's and Women's clothing.

The products other than textiles made from Lyocell fibres include Wipes, Medical swab, Bio Composites, Food casings, Flushable Papers, Glass Fibre Binder, Insulation Papers and Tea Bags.

On the grounds of its altitudinous modulus and shape constrainment, it finds its application in Industrial conveyor belts. Lyocell fibre supremely amalgamates with Cotton, Viscose, Hemp, Silk and Synthetic Fibres. Employing Lyocell fibres as raw materials, explorations on producing carbon fibre, tire cord, special papers etc have been consummated as laboratory research. 


\section{CONCLUSIONS}

Lyocell is the unique new inception cellulosic fibers brought into existence by a Dry Jet Wet spinning process. An intrinsic intent to its augmentation was the rush to probe for a process that is environmentally responsible and uses renewable resources as its raw materials. Lyocell fibre is very tenacious in wet or else dry, and it posses elevated resistance to pilling in comparison with cotton. Textile manufacturers are immensely attracted by its property to incorporate with other types of textile fibres. It is conveniently blended with Cotton, Silk, Rayon, Polyester, Nylon, and Wool. Lyocell fibre manufacture with NMMO is immensely favorable with the environment. If the aspiration is to build a sustainable fashion wardrobe, Lyocell will be the favorite. Accelerating the relevance and augmentation of Lyocell fibre commodity, reinforcing the ensuing market, contributing technical groundwork and endowing an exhaustive Industrial chain are a treasure to the Lyocell fibre Industrialization.

\section{REFERENCES}

1. https://www.sciencedirect.com/topics/engineering/lyocell-fiber

2. https://www.ispo.com/en/sustainability/new-trend-fiber-lyocell-everything-you-need-know-about-it

3. https://www.fabricromance.ie/blogs/journal/everything-you-need-to-know-about-tencel-and-modal

4. Abu-Rous, M.,Ingolic,E., \& Schuster, K(2006).

5. "Visualisation of the nano-structure of Tencel®(Lyocell) and other cellulosics as an approach to explaining functional \& wellness Properties in Textiles, Lenzinger Berichte 85, 31-37

6. Burrow, T.(1998). "Recent results with Lyocell fibres in Textiles", Lenz Ber 78,37-40

7. Ramamoorthy,S.K., Skrifvars, M., and Rissanen,M.(2014). "Effect of alkali \& silane surface treatments on regenerated cellulose fibre type(Lyocell) intended for composites", cellulose 22(1), 637-654 DOI:10.1007/s 10570-014-0526-6

8. Hailong Li., Jianguo Li(2018) "regenerated cellose by the Lyocell process, a brief review of the properties, Bioresources, March 2018

9. DOI:10.15376/biored.13.2.Zhang

10. Xiaoya Jiang, Yuanyuan Bai, Xuefeng Chen, Wen Liu, “A review on raw materials, commercial production \& properties of Lyocell fibre, Journal of Bioresources \&Biproducts

11. R.B.Chavan, AK Patra, "Development and processing Lyocell”, Indian Journal of Fibre\&Textile Research, Vol:29, December 2004, pp 483-492

12. Arun N, Manmade Text India, 43(1)(2000)33

13. Agarwal V, Man-made Text India, 44(6)(2001)215

14. Zhang,s., 2010 Preparing Regenerated Cellulose fibers using novel solution and its structure and properties, Donghua University, Shanghai.

15. Zhang, Y.P., Shao, H.L., Hu, X.C., 2001. Formation and characterization of cellulose membranes from N-MethylmorpholineN-Oxide Solution. Macromol. Biosci. 1. 141-148

16. Costa, A. F. S., MARIA ALICE VASCONCELOS Rocha, and L. A. Sarubbo. "Bacterial cellulose: an ecofriendly biotextile." International Journal of Textile and Fashion Technology 7: 11-26. 
17. Jalil, Mohammad Abdul, et al. "Analysis of physio-mechanical properties of jute-PALF Union fabrics." International Journal of Mechanical Engineering $4.3: 23-28$.

18. Maurya, N., et al. "Effect of Nanoparticles on Performance of Magneto-Rheological Fluids In Vibration Suppression." International Journal of Mechanical Engineering (IJME) 7. 5, ; 110.

19. Anchal Agarwal, Anil Jeengar, A Arputharaj, Manik Bhowmick, Kartick K Samanta, Prasad Satyamurthy, Charlene D’ Souza \& Nadanathangam Vigneshwaran, "Performance Characteristics of Electrospun Cellulose Acetate Nanofiber Mat Embedded with Nano-ZnO / Vitamins”, International Journal of Nanotechnology and Application (IJNA),Vol. 6, Issue 3, pp, 1-12 
